\title{
Research Article \\ Effects of the Argon Pressure on the Optical Band Gap of Zinc Oxide Thin Films Grown by Nonreactive RF Sputtering
}

\author{
M. Acosta, I. Riech, and E. Martín-Tovar \\ Materials Science Laboratory, Faculty of Engineering, Yucatan University, Avenida Industrias No Contaminantes S/N, \\ A.P. 150, Cordemex, 97000 Mérida, Yuc, Mexico \\ Correspondence should be addressed to M. Acosta; adiaz@uady.mx
}

Received 9 July 2013; Accepted 18 August 2013

Academic Editor: Chong-Xin Shan

Copyright (C) 2013 M. Acosta et al. This is an open access article distributed under the Creative Commons Attribution License, which permits unrestricted use, distribution, and reproduction in any medium, provided the original work is properly cited.

Zinc oxide $(\mathrm{ZnO})$ thin films were grown by nonreactive RF sputtering at room temperature under varying argon pressures $\left(P_{\mathrm{Ar}}\right)$. Their optical band gap was found to increase from 3.58 to $4.34 \mathrm{eV}$ when the argon pressure increases from 2.67 to $10.66 \mathrm{~Pa}$. After annealing at $200^{\circ} \mathrm{C}$ and $500^{\circ} \mathrm{C}$, optical band gaps decrease considerably. The observed widening of the band gap with increasing $P_{\mathrm{Ar}}$ can be understood as being a consequence of the poorer crystallinity of films grown at higher pressures. Measurements of morphological and electrical properties of these films correlate well with this picture. Our main aim is to understand the effects of $P_{\mathrm{Ar}}$ on several physical properties of the films, and most importantly on its optical band gap.

\section{Introduction}

$\mathrm{ZnO}$ is a wide-band-gap semiconductor with a high transparency in the whole visible range and electrical properties that can be tailored from insulating to semimetallic by doping. This has attracted strong interest in this material because of its potential for applications, which include transparent conducting electrodes, gas sensors, light emitting devices, laser diodes, and optical waveguides $[1,2]$.

$\mathrm{ZnO}$ thin films have been obtained by techniques such as sol-gel $[3,4]$, metal organic chemical vapor deposition $[5,6]$, pulsed laser deposition $[7,8]$, and sputtering $[9,10]$. As compared to other deposition methods, sputtering has several advantages. Uniformity of film thickness over large areas, a high degree of film adhesion, and relatively simple scalability properties are some of the most important advantages. Several recent works [11-14] discuss the mechanisms involved in $\mathrm{ZnO}$ thin film growth by magnetron sputtering in a mixture of argon and oxygen, that is, by reactive sputtering, at varying $\mathrm{Ar} / \mathrm{O}_{2}$ ratios. This technique produces films with a fixed optical band gap, in the absence of doping.

Most applications of $\mathrm{ZnO}$ as a semiconductor, on the other hand, require the tailoring of the band gap. Band gap modulation of $\mathrm{ZnO}$ is usually obtained by doping with $\mathrm{Cd}$ and $\mathrm{Mg}$ ions [15]. A significant widening of the band gap, reaching values as high as $5.23 \mathrm{eV}$, has been reported for $\mathrm{ZnMgO}$ films $[16,17]$. However, doping may sometimes be undesirable, for example, because this may compromise the crystallographic properties of the film [17]. Therefore, there is a strong interest in exploring different approaches to control the band gap in $\mathrm{ZnO}$ films.

An approach to control band gap that has not been widely explored up to now consists in depositing $\mathrm{ZnO}$ from a ceramic target, without the addition of $\mathrm{O}_{2}$, under varying Ar pressures. This procedure, as we report here, allows one to modify the band gap without doping. In this work, we show that the optical band gap of $\mathrm{ZnO}$ films can be tuned from 3.58 to $4.34 \mathrm{eV}$, when depositing by the above mentioned procedure with Ar pressures is in the range from 2.67 to 10.66 Pa.

As-deposited films were polycrystalline with low intensity diffraction peaks corresponding to the wurtzite hexagonal phase of $\mathrm{ZnO}$. After annealing at temperatures of $200^{\circ} \mathrm{C}$ and $500^{\circ} \mathrm{C}$ in air, the polycrystalline films became c-orientated with high intensity (002) diffraction peak. The surfaces of asgrown films were smooth, with an average roughness of $12 \AA$. Their morphology changed drastically after crystallization, showing average roughness ranging from 40 to $60 \AA$. All films had transmittance values above $90 \%$ in the whole visible range. While resistivities of as-grown films were larger than 
TABLE 1: Argon pressure dependence of $2 \theta$ values for (002) peaks, crystallite sizes, and deposition rate.

\begin{tabular}{lccccc}
\hline$P_{\mathrm{Ar}}$ & \multicolumn{2}{c}{$2 \theta(002)$ peak } & \multicolumn{2}{c}{ Crystallite size $(\mathrm{nm})$} & Deposition \\
$(\mathrm{Pa})$ & $200^{\circ} \mathrm{C}$ & $500^{\circ} \mathrm{C}$ & $200^{\circ} \mathrm{C}$ & $500^{\circ} \mathrm{C}$ & rate $(\AA / \mathrm{min})$ \\
\hline 2.67 & 34.38 & 34.41 & 11.7 & 14.0 & 330 \\
5.33 & 34.33 & 34.45 & 12.6 & 14.4 & 260 \\
8.00 & 34.38 & 34.44 & 12.2 & 14.6 & 130 \\
10.66 & 34.40 & 34.42 & 11.5 & 13.8 & 110 \\
\hline
\end{tabular}

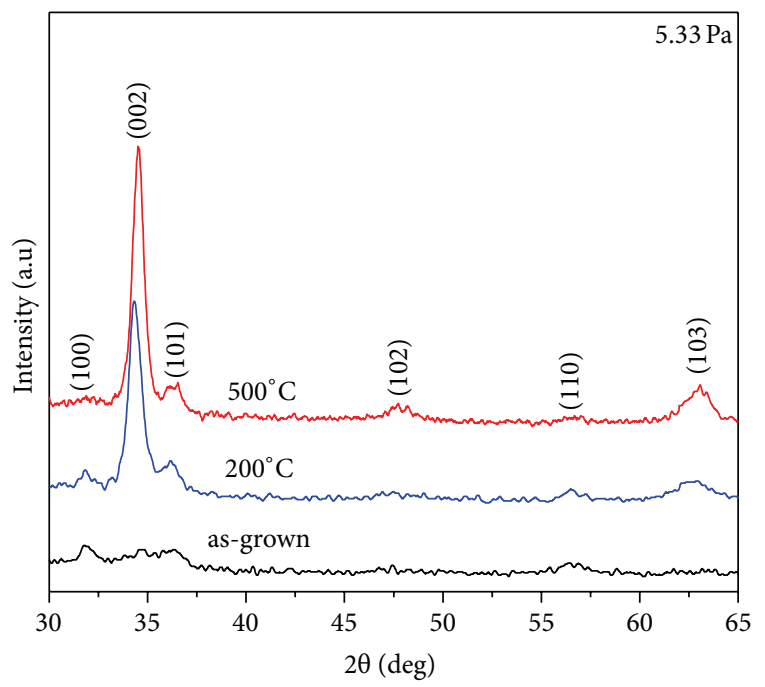

FIgURE 1: Typical XRD patterns for as-grown film and after thermal annealing at $200^{\circ} \mathrm{C}$ and $500^{\circ} \mathrm{C}$.

$10^{7} \Omega \mathrm{cm}$ at $302 \mathrm{~K}$, these were found to range from $10^{3} \Omega \mathrm{cm}$ $\left(P_{\mathrm{Ar}}=2.67 \mathrm{~Pa}\right)$ to $10^{6} \Omega \mathrm{cm}\left(P_{\mathrm{Ar}}=10.66 \mathrm{~Pa}\right)$ after annealing at $200^{\circ} \mathrm{C}$ and from $10^{-1} \Omega \mathrm{cm}$ to $10^{1} \Omega \mathrm{cm}$ after annealing at $500^{\circ} \mathrm{C}$.

\section{Experimental Details}

Zinc oxide thin films were grown on Corning glass 2947 substrates by RF magnetron sputtering technique. All films were prepared using an INTERCOVAMEX-V3 sputtering system with a Lesker's Torus magnetron gun connected to a 600 watt advanced energy RF power. All films were grown at room temperature, using a $3 \mathrm{in}$. diameter $\mathrm{ZnO}$ target (Kurt J. Lesker, 99.9\% purity). An on-axis configuration was used for the sputtering process. The distance between the target and the substrate was kept at $2.5 \mathrm{~cm}$. The vacuum chamber was evacuated by a turbo molecular pump to a base pressure lower than $10^{-4} \mathrm{~Pa}$ before deposition. The target was then presputtered during 10 minutes to remove any contamination from its surface. Argon pressures ranged from 2.67 to $10.66 \mathrm{~Pa}$, in steps of $2.67 \mathrm{~Pa}$. The RF power was $100 \mathrm{~W}$ and growth time was $10 \mathrm{~min}$ in all cases.

Film morphology was determined with the help of a Nanosurf atomic force microscopy (AFM) and using a NanoWorld silicon probe in contact mode (constant force
$0.18 \mathrm{~N} / \mathrm{m}$, resonance frequency $14 \mathrm{kHz}$ ). The mean roughness values reported in this work are arithmetic averages of the absolute surface height measured from the mean plane. These were provided by the Easy-Scan AFM analysis software. Structural properties of films were obtained by Xray diffraction $(\mathrm{XRD})$, using a Siemens D500 diffractometer equipped with $\mathrm{Cu} \mathrm{K}_{\alpha}$ radiation $(\lambda=0.154 \mathrm{~nm})$. Film thicknesses were measured using a profiler Veeco Dektak 8 Stylus. Transmittance spectra were recorded with the help of an Agilent 8453 UV-Vis spectrophotometer. Resistivity values were obtained with an Ecopia HMS-5000 Van der Pauw measurement system at $302 \mathrm{~K}$.

\section{Results and Discussion}

3.1. Structure and Morphology. Figure 1 shows XRD spectra for as-grown films and after thermal annealing. As-grown films were polycrystalline with low intensity (100), (101), and (110) diffraction peaks corresponding to hexagonal wurtzite structure of $\mathrm{ZnO}$ (JCPDS 36-1451) [18]. After annealing at $200^{\circ} \mathrm{C}$ and $500^{\circ} \mathrm{C}$ during $2 \mathrm{~h}$ in air, a preferred orientation along (002) plane was evident, indicating an improved crystallinity orientation of the $\mathrm{ZnO}$ films along the $c$-axis. The intensity of the (002) peak increased, and its $2 \theta$ value shifted toward a higher angle, with increasing annealing temperature. As shown in Table 1 , the $2 \theta$ values of (002) peaks for films annealed at $200^{\circ} \mathrm{C}$ are slightly smaller than $2 \theta=$ $34.422^{\circ}$, as reported for JCPDs 36-1451 [18]. This suggests the existence of compressive strain in $c$-axis direction. This residual stress was released after annealing at $500^{\circ} \mathrm{C}$, as evidenced by measured values of $2 \theta$ of around 34.42. During the annealing process, the atoms of $\mathrm{ZnO}$ films gain more kinetic energy and their vibration amplitude grows. This kinetic energy of the atoms allows them to rearrange in the crystal lattice releasing the compressive stress. Similar results have been reported in the literature previously $[19,20]$.

Crystallite sizes were estimated using Scherrer's equation [21], considering the FWHM and $2 \theta$ values of (002) peaks, see Table 1. As seen in Table 1, crystallite sizes were independent of $P_{\mathrm{Ar}}$ at a fixed annealing temperature. However, the average crystallite size increased from $12 \mathrm{~nm}$ for films annealed at $200^{\circ} \mathrm{C}$ to $14.2 \mathrm{~nm}$ after annealing at $500^{\circ} \mathrm{C}$, as a consequence of the Ostwald ripening process where atoms migrate forming larger crystallites.

Table 1 shows that deposition rates decrease when $P_{\mathrm{Ar}}$ increases from $2.67 \mathrm{~Pa}$ to $10.66 \mathrm{~Pa}$. These variations can be attributed to changes in the mean-free path of the sputtered species in the background argon gas. As $P_{\mathrm{Ar}}$ increases, the sputtered species undergoes a higher number of collisions; hence, fewer particles arrive at the substrate with the subsequent decrease in deposition rates [22, 23].

As-grown films had smooth surfaces, with an average roughness of $12 \AA$. Figure 2 (a) shows an AFM image of a typical as-deposited film. A dense film structure, without pores or defects, can be observed. After annealing at $200^{\circ} \mathrm{C}$ and $500^{\circ} \mathrm{C}$ in air, sample morphology changed significantly due to crystallization; see Figures 2(b) and 2(c). Average roughness increased to $38 \AA$ after annealing at $200^{\circ} \mathrm{C}$ and 


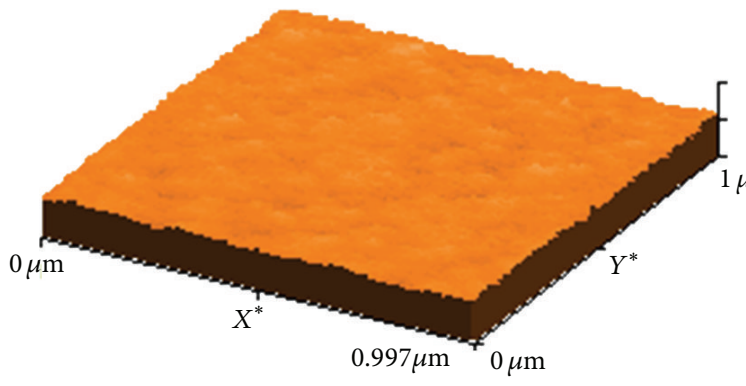

(a)

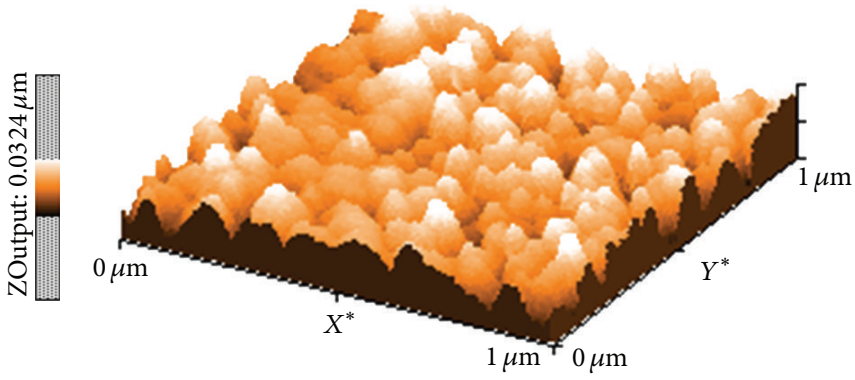

(b)

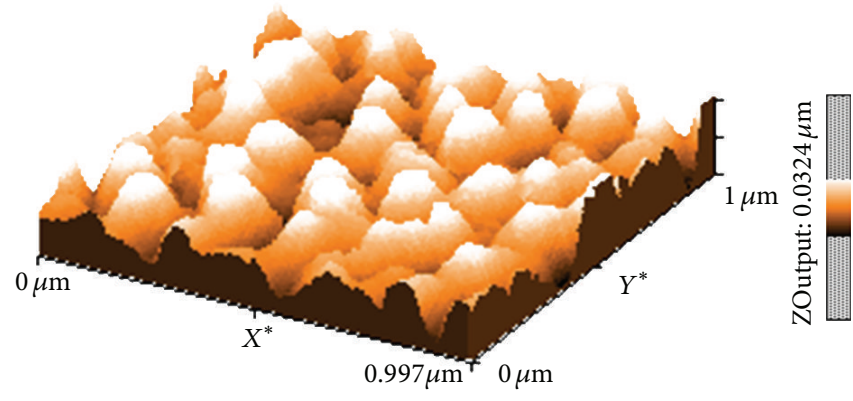

(c)

Figure 2: AFM image of (a) typical as-deposited film $\left(P_{\mathrm{Ar}}=2.67 \mathrm{~Pa}\right),(\mathrm{b})$ the same film, after annealing at $200^{\circ} \mathrm{C}$, and $(\mathrm{c})$ after annealing at $500^{\circ} \mathrm{C}$. For all images $z$ output $=32 \mathrm{~nm}$.

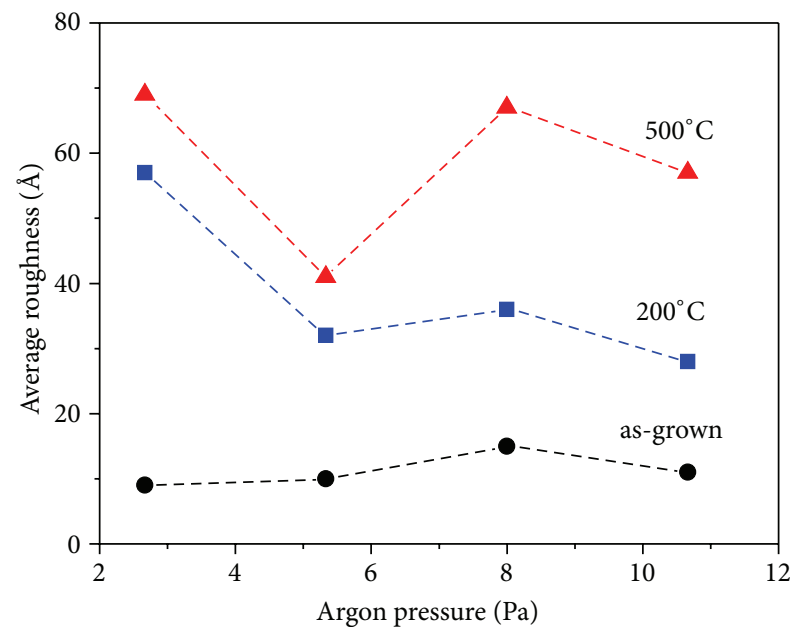

FIGURE 3: Average roughness of films as a function of argon pressure, for different annealing temperatures.

to $59 \AA$ after annealing at $500^{\circ} \mathrm{C}$; see Figure 3. AFM images showed that these increases are to be correlated with the appearance of what resembled a hill-valley structure throughout the entire film surface. The observed surface roughening after the annealing process can be ascribed to the Ostwald ripening process, where atoms migrate to reduce surface energy forming larger grains, as can be seen in AFM images.

3.2. Optical and Electrical Properties. Figure 4 shows the wavelength dependence of transmittance for films grown

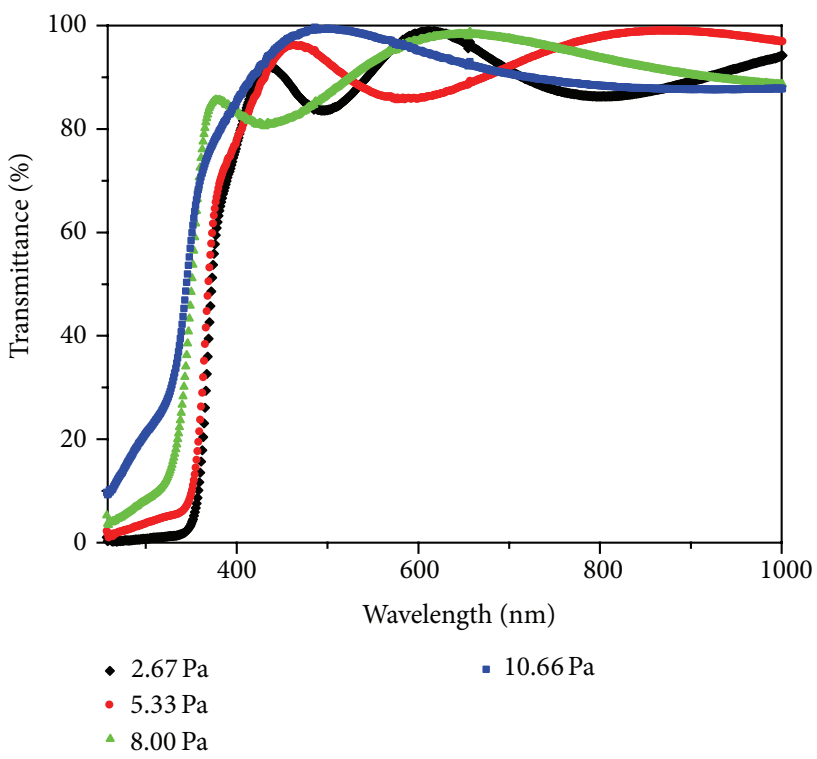

FIGURE 4: Transmittance spectra for films grown with varying argon pressures.

with $P_{\mathrm{Ar}}$ ranging from 2.67 to $10.66 \mathrm{~Pa}$. All transmittances were larger than $90 \%$ in the visible range. Notice that the absorption edge shifts towards shorter wavelengths with increasing $P_{\mathrm{Ar}}$.

In Figure 4, an increasing tail is observed for $\lambda<400 \mathrm{~nm}$ when $P_{\mathrm{Ar}}$ increases. Similar tails in the transmittance spectra of $\mathrm{ZnO}$ films have been observed previously [6, 24, 25]. These 


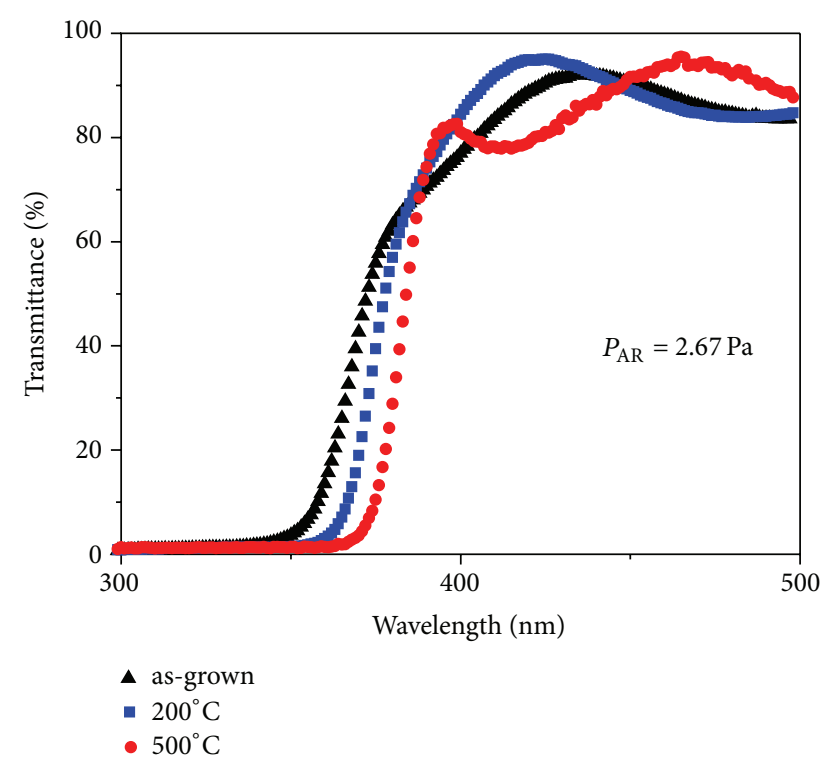

FIgURE 5: Transmittance spectra for film grown with $P_{\mathrm{Ar}}=2.67 \mathrm{~Pa}$ before and after annealing at $200^{\circ} \mathrm{C}$ and $500^{\circ} \mathrm{C}$.

tails have been correlated with poor crystallinity of films [26]. A possible explanation for our observation of increasing tail regions for increasing $P_{\mathrm{Ar}}$ (see Figure 4 ) is as follows. Our experiment was conducted in a high $P_{\text {Ar }}(>2 \mathrm{~Pa})$ regime, where transport is mostly diffusive [27]. Hence, sputtered species were thermalized by collision before reaching the substrate. Therefore, incident atoms had little energy available to diffuse across the surface, leading to poor crystallinity in the growing film.

After annealing, the average transmittance of $\mathrm{ZnO}$ films did not change significantly, but the optical absorption edge shifted to longer wavelengths (see Figure 5). It is known $[28,29]$ that oxygen vacancies modify the absorption edge for $\mathrm{ZnO}$ films. In our study, it is reasonable to assume that the density of oxygen vacancies increased for increasing annealing temperature. This provides a possible explanation for the observed shifts.

Optical band gaps were determined by extrapolation from a linear fit of absorption coefficients in the highenergy region. Assuming parabolic valence and conduction bands, the absorption coefficient of a semiconductor near the absorption edge is given by [30] as follows: $\alpha=B\left(h \nu-E_{q}\right)^{n}$, where $B$ is a constant, $E_{g}$ is the optical band gap, and $n$ is a coefficient that equals $1 / 2$ for allowed direct transitions. Figure 6 shows the optical band gap energy as a function of $P_{\mathrm{Ar}}$, before and after annealing. These values increase from $3.58 \mathrm{eV}$ for $P_{\mathrm{Ar}}=2.67 \mathrm{~Pa}$ to $4.34 \mathrm{eV}$ for $P_{\mathrm{Ar}}=10.66$. Our optical gap values are larger than those reported for undoped $\mathrm{ZnO}$ thin films [2]. Similar optical band gap shifts to values of around $4 \mathrm{eV}$ have been reported by Tan et al. [31]. These authors propose that the amorphous phase in these films is the main reason for the increase in optical band gaps. This explanation is consistent with the observed increases in

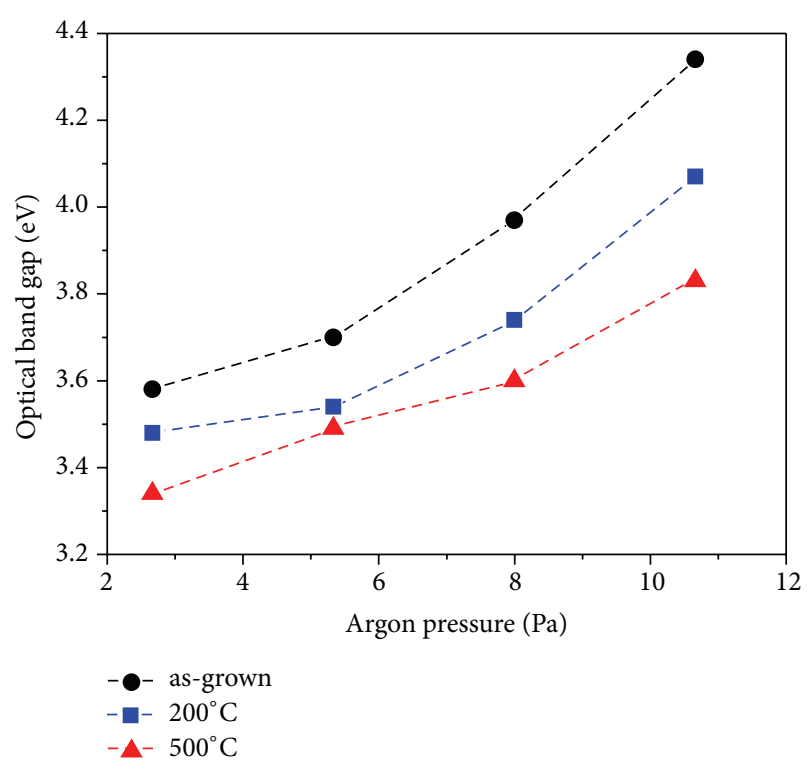

FIGURE 6: Optical energy band gap values as a function of $P_{\mathrm{Ar}}$, before and after annealing at $200^{\circ} \mathrm{C}$ and $500^{\circ} \mathrm{C}$.

transmittance tails in Figure 4, which have been correlated with poor crystallinity $[26,31]$.

Relying on the XRD results, it seems reasonable to assume that the widening of the optical band gap is due to the reduced crystallinity of our films. As the $P_{\mathrm{Ar}}$ increases sputtered atoms lost kinetic energy, so the fraction of amorphous $\mathrm{ZnO}$ increases. In fact there are only low intensity (100), (101), and (110) diffraction peaks in the XRD pattern for as-grown films (Figure 1). The physical model about the change of optical band gap induced by increasing $P_{\mathrm{Ar}}$ can be viewed as crystalline regions embedded in a matrix of amorphous $\mathrm{ZnO}$. As a result, the absorption of photon is mainly contributed by amorphous $\mathrm{ZnO}$. On the other hand, after annealing, the crystalline quality of $\mathrm{ZnO}$ films improves, and consequently the optical band gap decreases considerably. Amorphous phase as a possible cause of the widening of the optical band gap in polycrystalline $\mathrm{ZnO}$ films has also been reported by Mera et al. [32].

After annealing, band gap values decreased considerably. In the case of $P_{\mathrm{Ar}}=2.67 \mathrm{~Pa}$, for example, the as-grown $E_{g}$ was $3.37 \mathrm{eV}$, but it decreased to $3.24 \mathrm{eV}$ after annealing at $500^{\circ} \mathrm{C}$. This is consistent with our earlier discussion of transmittance results and its relation with oxygen vacancies and crystallization process. Thermal annealing favors oxygen desorption, thus leading to a decrease in $E_{g}$. Li et al. reported that substrate temperatures have a similar effect on the optical band gap values of $\mathrm{ZnO}$ films [33]. Hiramatsu et al. have found that the intensity of $\mathrm{O}_{2}$ desorption from $\mathrm{ZnO}$ films increases rapidly for temperatures larger than $300^{\circ} \mathrm{C}$ [34].

$\mathrm{ZnO}$ is an important semiconductor with a wide range of applications in electronic devices. Therefore, the investigation of its electrical properties is important. The resistivities of our films at room temperature, before annealing, were higher than $10^{7} \Omega \mathrm{cm}$, which is the experimental detection limit of 
TABLE 2: Resistivity values as a function of $P_{\mathrm{Ar}}$ for films annealed at 200 and $500^{\circ} \mathrm{C}$.

\begin{tabular}{lcc}
\hline$P_{\mathrm{Ar}}(\mathrm{Pa})$ & \multicolumn{2}{c}{ Resistivity $(\Omega \mathrm{cm})$ at $302 \mathrm{~K}$} \\
& $200^{\circ} \mathrm{C}$ & $500^{\circ} \mathrm{C}$ \\
\hline 2.67 & $3.7 \times 10^{3}$ & $1.8 \times 10^{-1}$ \\
5.33 & $5.9 \times 10^{4}$ & $4.3 \times 10^{-1}$ \\
8.00 & $6.2 \times 10^{4}$ & $8.5 \times 10^{-1}$ \\
10.66 & $1.1 \times 10^{6}$ & $2.4 \times 10^{1}$ \\
\hline
\end{tabular}

our Hall system. Resistivities after annealing at $200^{\circ} \mathrm{C}$ and $500^{\circ} \mathrm{C}$ are shown in Table 2. The observed decrease in resistivity with increasing annealing temperature can be ascribed to oxygen desorption and to crystallization, in accordance with our discussion above. After annealing, the crystalline quality increased, which also will cause the decrease of resistivity due to the weakening of the grain boundary scattering. The large resistivity of as-grown films might make them apt for buffer layers in flexible solar cells [35].

\section{Conclusions}

The present work investigated the effect of varying the argon pressure on the morphological, optical, and electrical properties of zinc oxide films grown by RF sputtering from a $\mathrm{ZnO}$ target. Additionally, the influence of the annealing, temperature was also studied. Relying on XRD measurements the films were polycrystalline and became c-orientated after annealing at $200^{\circ} \mathrm{C}$ and $500^{\circ} \mathrm{C}$. The main result of this investigation is that optical band gap values increase from $3.58 \mathrm{eV}$ to $4.34 \mathrm{eV}$ when the argon pressure increases from 2.67 to $10.66 \mathrm{~Pa}$. The observed widening of the optical band gap can be understood as being due to changes in the meanfree path of the sputtered species in the background argon gas, which in turn influences the degree of crystallinity of the films. Optical band gaps and resistivities were found to decrease after annealing, which is consistent with oxygen desorption and the improvement of the crystalline quality of films during this process. Our results demonstrate that the optical properties of $\mathrm{ZnO}$ films grown under the conditions of our experiment can be tuned by controlling the argon pressure.

\section{Acknowledgments}

The authors would like to thank Daniel Aguilar and Patricia Quintana for XRD analysis and Willian Cauich for film thickness measurements. The financial support from FORDECYT116157 is gratefully acknowledged.

\section{References}

[1] V. Coleman, C. Jagadish, and D. Look, Zinc Oxide Bulk, Thin Films and Nanostructures, Processing, Properties and Applications, Elsevier, 2006.

[2] K. Ellmer, A. Klein, and B. Rech, Transparent Conductive Zinc Oxide Basics and Applications in Thin Film Solar Cells, Springer, 2008.
[3] L. Xu, X. Li, Y. Chen, and F. Xu, "Structural and optical properties of $\mathrm{ZnO}$ thin films prepared by sol-gel method with different thickness," Applied Surface Science, vol. 257, no. 9, pp. 4031-4037, 2011.

[4] M. Vishwas, K. N. Rao, A. R. Phani, K. V. A. Gowda, and R. P. S. Chakradhar, "Effect of annealing temperature on electrical and nano-structural properties of sol-gel derived $\mathrm{ZnO}$ thin films," Journal of Materials Science, vol. 22, no. 9, pp. 1415-1419, 2011.

[5] B. H. Kong, D. C. Kim, S. K. Mohanta, and H. K. Cho, "Influence of VI/II ratios on the growth of $\mathrm{ZnO}$ thin films on sapphire substrates by low temperature MOCVD," Thin Solid Films, vol. 518, no. 11, pp. 2975-2979, 2010.

[6] K. Seomoon, J. Lee, P. Jang, C. Jung, and K.-H. Kim, "Synthesis and characterization of $\mathrm{ZnO}$ thin films deposited via PEMOCVD," Current Applied Physics, vol. 11, no. 4, pp. S26-S29, 2011.

[7] B. L. Zhu, X. Z. Zhao, F. H. Su et al., "Low temperature annealing effects on the structure and optical properties of $\mathrm{ZnO}$ films grown by pulsed laser deposition," Vacuum, vol. 84, no. 11, pp. 1280-1286, 2010.

[8] M. Stamataki, I. Fasaki, G. Tsonos, D. Tsamakis, and M. Kompitsas, "Annealing effects on the structural, electrical and $\mathrm{H}_{2}$ sensing properties of transparent $\mathrm{ZnO}$ thin films, grown by pulsed laser deposition," Thin Solid Films, vol. 518, no. 4, pp. 1326-1331, 2009.

[9] V. Tvarozek, I. Novotny, P. Sutta, S. Flickyngerova, K. Schtereva, and E. Vavrinsky, "Influence of sputtering parameters on crystalline structure of $\mathrm{ZnO}$ thin films," Thin Solid Films, vol. 515, no. 24, pp. 8756-8760, 2007.

[10] S. Mukhtar, A. Asadov, and W. Gao, "Microstructure of $\mathrm{ZnO}$ thin films produced by magnetron sputter oblique deposition," Thin Solid Films, vol. 520, no. 9, pp. 3453-3457, 2012.

[11] P.-T. Hsieh, Y.-C. Chen, K.-S. Kao, and C.-M. Wang, "Structural and luminescent characteristics of non-stoichiometric $\mathrm{ZnO}$ films by various sputtering and annealing temperatures," Physica B, vol. 403, no. 1, pp. 178-183, 2008.

[12] T. Matsuda, M. Furuta, T. Hiramatsu, H. Furuta, C. Li, and T. Hirao, "Thermal stability of $\mathrm{ZnO}$ thin film prepared by RF-magnetron sputtering evaluated by thermal desorption spectroscopy," Applied Surface Science, vol. 256, no. 21, pp. 63506353, 2010.

[13] M. Furuta, T. Hiramatsu, T. Matsuda, C. Li, H. Furuta, and T. Hirao, "Oxygen bombardment effects on average crystallite size of sputter-deposited $\mathrm{ZnO}$ films," Journal of Non-Crystalline Solids, vol. 354, no. 17, pp. 1926-1931, 2008.

[14] S.-R. Jian, H.-G. Chen, G.-J. Chen, J. S. C. Jang, and J.-Y. Juang, "Structural and nanomechanical properties of a-plane $\mathrm{ZnO}$ thin films deposited under different oxygen partial pressures," Current Applied Physics, vol. 12, no. 3, pp. 849-853, 2012.

[15] A. Janotti and C. G. Van de Walle, "Fundamentals of zinc oxide as a semiconductor," Reports on Progress in Physics, vol. 72, no. 12, Article ID 126501, 2009.

[16] D. Wang, T. Narusawa, T. Kawaharamura, M. Furuta, and C. Li, "Influence of sputtering pressure on band gap of $\mathrm{Zn}_{1-x} \mathrm{Mg}_{x} \mathrm{O}$ thin films prepared by radio frequency magnetron sputtering," Journal of Vacuum Science \& Technology B, vol. 29, no. 5, Article ID 051205, 2011.

[17] P. Kumar, J. P. Singh, Y. Kumar, A. Gaur, H. K. Malik, and K. Asokan, "Investigation of phase segregation in $\mathrm{Zn}_{1-x} \mathrm{Mg}_{x} \mathrm{O}$ systems," Current Applied Physics, vol. 12, no. 4, pp. 1166-1172, 2012. 
[18] Powder Diffraction File, Joint Committee on Powder Diffraction Standards, ASTM, Philadelphia, Pa, USA, 2003, Card 36-1451.

[19] S.-Y. Chu, W. Water, and J.-T. Liaw, "Influence of postdeposition annealing on the properties of $\mathrm{ZnO}$ films prepared by $\mathrm{RF}$ magnetron sputtering," Journal of the European Ceramic Society, vol. 23, no. 10, pp. 1593-1598, 2003.

[20] D. Raoufi and T. Raoufi, "The effect of heat treatment on the physical properties of sol-gel derived $\mathrm{ZnO}$ thin films," Applied Surface Science, vol. 255, no. 11, pp. 5812-5817, 2009.

[21] E. Bertaud, International Tables for X-Ray Crystallography, Kynoch Press, Birmingham, UK, 1968.

[22] W. Z. Liu, H. Y. Xu, L. Wang, X. H. Li, and Y. C. Liu, "Sizecontrolled growth of $\mathrm{ZnO}$ nanowires by catalyst-free highpressure pulsed laser deposition and their optical properties," AIP Advances, vol. 1, no. 2, Article ID 022145, 8 pages, 2011.

[23] R. E. Somekh, "Calculations of thermalization during the sputter deposition process," Vacuum, vol. 34, no. 10-11, pp. 987990, 1984.

[24] M. Hezam, N. Tabet, and A. Mekki, "Synthesis and characterization of DC magnetron sputtered $\mathrm{ZnO}$ thin films under high working pressures," Thin Solid Films, vol. 518, no. 24, pp. e161e164, 2010.

[25] Y. Caglar, M. Caglar, and S. Ilican, "Microstructural, optical and electrical studies on sol gel derived $\mathrm{ZnO}$ and $\mathrm{ZnO}: \mathrm{Al}$ films," Current Applied Physics, vol. 12, no. 3, pp. 963-968, 2012.

[26] E. Kim, Z.-T. Jiang, and K. No, "Measurement and calculation of optical band gap of chromium aluminum oxide films," Japanese Journal of Applied Physics 1, vol. 39, no. 8, pp. 4820-4825, 2000.

[27] S. M. Rossnagel, I. Yang, and J. J. Cuomo, "Compositional changes during magnetron sputtering of alloys," Thin Solid Films, vol. 199, no. 1, pp. 59-69, 1991.

[28] S. Kishimoto, T. Yamada, K. Ikeda, H. Makino, and T. Yamamoto, "Effects of oxygen partial pressure on film growth and electrical properties of undoped $\mathrm{ZnO}$ films with thickness below 100 nm," Surface and Coatings Technology, vol. 201, no. 7, pp. 4000-4003, 2006.

[29] D. B. Buchholz, D. E. Proffit, M. D. Wisser, T. O. Mason, and R. P. H. Chang, "Electrical and band-gap properties of amorphous zinc-indium-tin oxide thin films," Progress in Natural Science, vol. 22, no. 1, pp. 1-6, 2012.

[30] J. Tauc, Amorphous and Liquid Semiconductors, Plenum Press, New York, NY, USA, 1974.

[31] S. T. Tan, B. J. Chen, X. W. Sun et al., "Blueshift of optical band gap in $\mathrm{ZnO}$ thin films grown by metal-organic chemical-vapor deposition," Journal of Applied Physics, vol. 98, no. 1, Article ID 013505, 2005.

[32] J. Mera, C. Cordoba, A. Gómez, C. Paucar, and O. Morán, "Amorphous phase as possible origin of additional absorption bands in polycrystalline ZnO films," Journal of Non-Crystalline Solids, vol. 358, no. 23, pp. 3229-3233, 2012.

[33] X. H. Li, A. P. Huang, M. K. Zhu et al., "Influence of substrate temperature on the orientation and optical properties of sputtered $\mathrm{ZnO}$ films," Materials Letters, vol. 57, no. 30, pp. 46554659, 2003.

[34] T. Hiramatsu, M. Furuta, T. Matsuda, C. Li, and T. Hirao, "Behavior of oxygen in zinc oxide films through thermal annealing and its effect on sheet resistance," Applied Surface Science, vol. 257, no. 13, pp. 5480-5483, 2011.

[35] A. Shimizu, S. Chaisitsak, T. Sugiyama, A. Yamada, and M. Konagai, "Zinc-based buffer layer in the $\mathrm{Cu}(\mathrm{InGa}) \mathrm{Se}_{2}$ thin film solar cells," Thin Solid Films, vol. 361, pp. 193-197, 2000. 

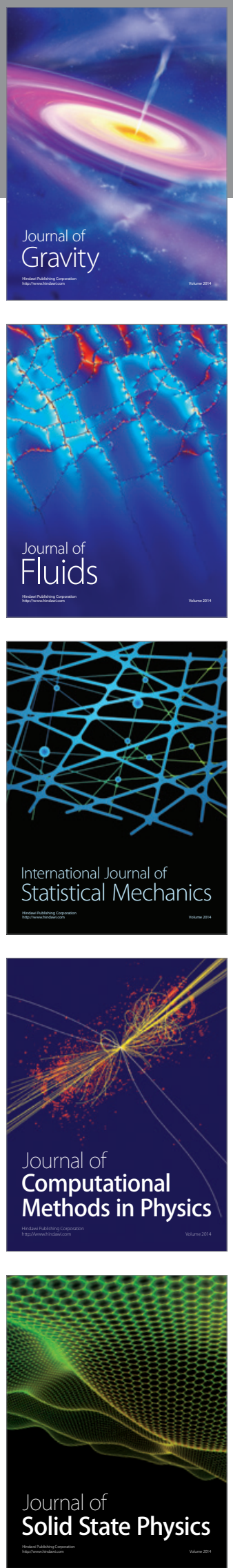

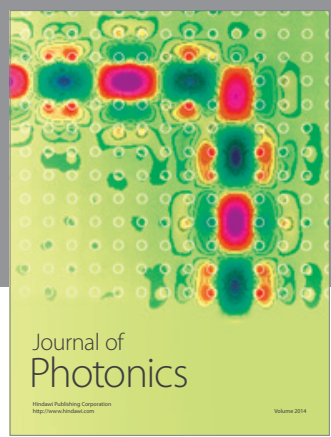

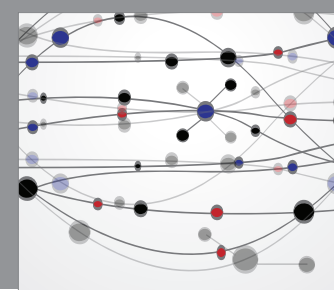

The Scientific World Journal

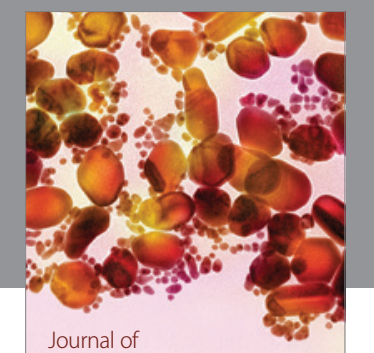

Soft Matter
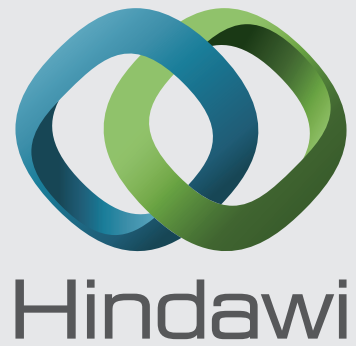

Submit your manuscripts at

http://www.hindawi.com
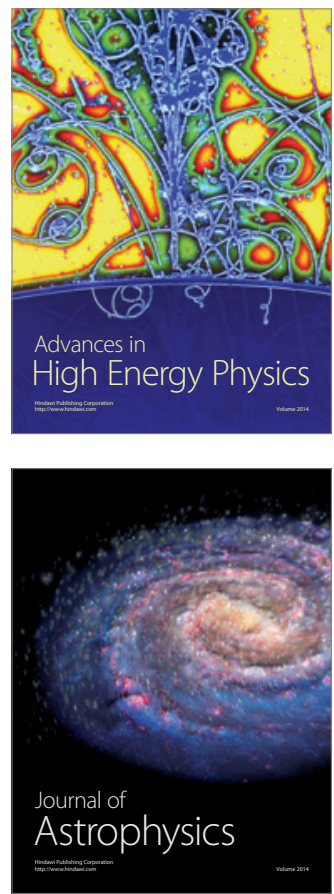
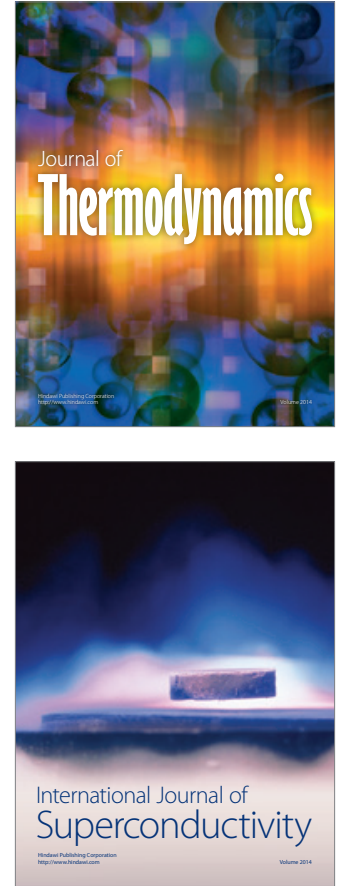
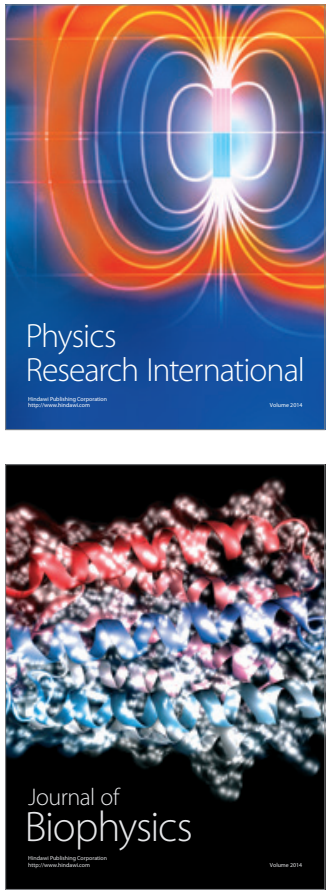
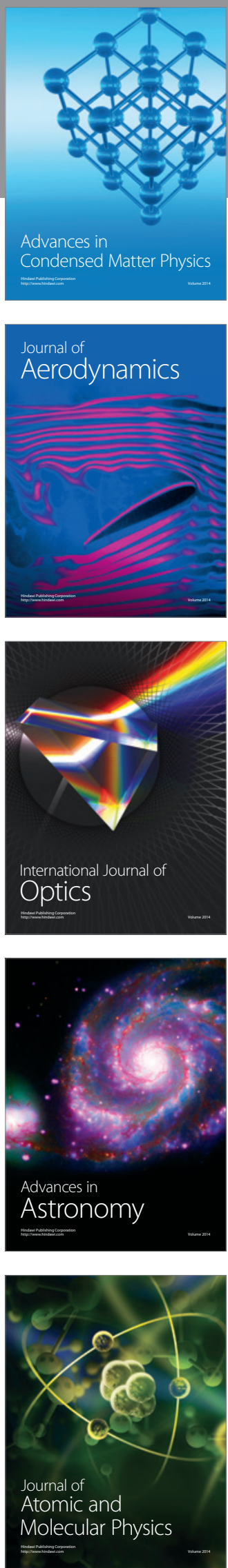